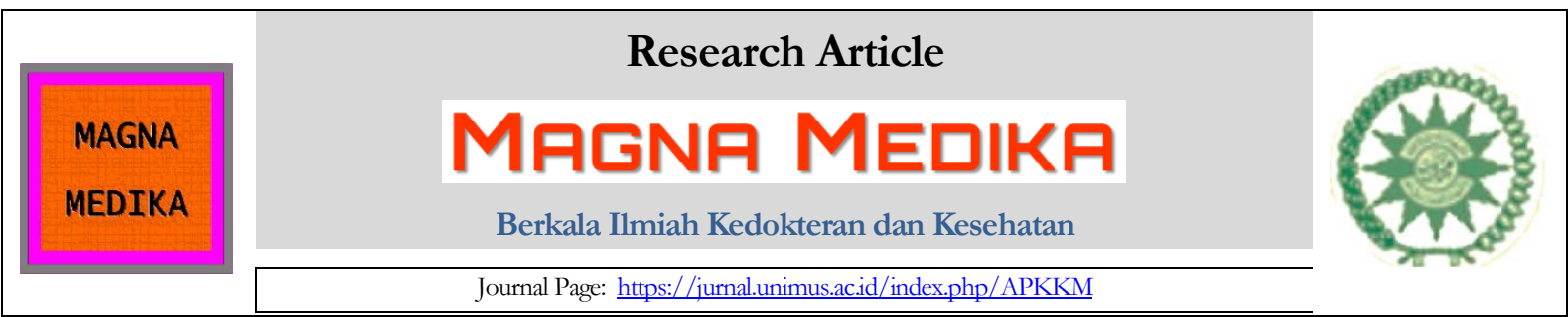

\title{
Differences Characteristics of Partial Bowel Obstruction and Total Bowel Obstruction in Ileus Patients at Dr. Soegiri Lamongan Hospital
}

\author{
Syeila Ainun Nisa ${ }^{1}$, Yohni Wahyu Finansah', Uning Marlina ${ }^{3}$, Syaiful Rochman ${ }^{4}$ \\ 1,3,3,4) Medical Faculty, University Muhammadiyah of Surabaya
}

\begin{tabular}{l}
\hline \multicolumn{1}{c}{ Article Info } \\
\hline Article history: \\
Received 13 December 2020 \\
Revised 10 January 2021 \\
Accepted 12 January 2021 \\
Available online 01 February 2021 \\
\hline Keywords: \\
Partial, Total, Bowel, Ileus, \\
Obstruction \\
\hline Correspondence: \\
birumerah203@gmail.com \\
\hline
\end{tabular}

How to cite this article: 1. NisaSA, Finansah YW, Marlina U, Rochman S. Differences Characteristics of Partial Bowel Obstruction and Total Bowel Obstruction in Ileus Patients at Dr. Soegiri Lamongan Hospital. MAGNA MEDIKA Berk Ilm Kedokt dan Kesehat. 2021;8(1):29-34

\begin{abstract}
Background: Across all age ranges, one in a thousand people is diagnosed with ileus annually. Ileus is categorized into two types, obstructive ileus, and paralytic ileus. Obstructive ileus is a condition where intestinal passage disorder occurs as a result of a mechanical blockage. There are 7,024 obstructive ileus without hernia in Indonesia and 7,059 paralytic ileus cases in 2004.
\end{abstract}

Purpose: To understand the comparison of characteristics of obstructive ileus patients.

Method: This analytic descriptive research use the cross-sectional method. Samples are diagnosed with ileus based on the laparotomy result from RSUD Dr. Soegiri, Lamongan. The sampling method is total sampling based on 2015-2019 data. The samples were also using secondary data from medical records, from December 2019 to January 2020.

Result: Respondents are mostly male with ages 65 years and over, less than ten days treatment duration, 39 minutes in the average length of partial bowel obstruction surgery duration, 42 minutes in the average length of total bowel obstruction surgery duration, less than two days treatment duration before surgery, percentage of ICU admission as high as $51.5 \%$, and blood transfusion percentage on $6.1 \%$. There are significant differences in the characteristics of ileus patient's age ( $\mathrm{p}$-value $0,021)$.

Conclusion: Based on this study, it can be concluded that there are differences based on age in the characteristics of partial bowel obstruction and total bowel obstruction on ileus patients, whereas gender, treatment duration, treatment duration before surgery, and surgery duration did not deliver any differences. 


\section{PENDAHULUAN}

Menurut WHO (1998) mengatakan bahwa pada tahun 2020 penyakit saluran pencernaan berada dalam 10 besar penyakit yang mengakibatkan kematian di dunia. Menurut WHO (2007) penyakit saluran pencernaan termasuk dalam urutan ke-7 di Malaysia pada tahun 2007 dengan jumlah 1809 kasus. Penyakit saluran pencernaan di Indonesia menempati urutan ke-3 penyakit utama yang dapat menyebabkan kematian, data dari Ditjen Bina Yanmedik Depkes RI menunjukkan total kematian 6.590 kasus pada tahun 2007 dan 6.825 total kasus kematian pada tahun $2008^{1}$. Akut abdomen menjadi salah gejala yang sering dikeluhkan pasien ke dokter. Sekitar $60 \%$ - $90 \%$ kasus ileus menjadi penyebab akut abdomen yang bukan apendisitis akut ${ }^{2}$. Menurut Ansari P (2007) dari segala usia, setiap tahun ada 1 dari 1000 orang yang terdiagnosa ileus. Terdapat 2 macam ileus, yakni ileus obstruktif dan ileus paralitik. Ileus obstruktif merupakan pasase usus yang terganggu akibat sumbatan mekanik. Sedangkan ileus paralitik merupakan peristiwa peristaltik usus yang terhenti akibat adanya peradangan pada lesi saraf ataupun terjepitnya lesi saraf sehingga memicu saraf yang mengalami kelumpuhan ${ }^{3}$. Menurut Mukherjee, S (2008) data dari rumah sakit yang ada di Australia pada tahun 2001-2002 menyebutkan, pasien yang diopname karena penyakit ileus obstruktif dan ileus paralitik diperkirakan 6,5 per 10.000 penduduk. Di Indonesia, terdapat 7.024 kasus ileus obstruktif tanpa hernia dan 7.059 kasus ileus paralitik pada tahun $2004^{4}$.

Angka kejadian penyakit ileus di RSUD DR Soegiri Lamogan pada tahun 2016 tercatat 40 kasus ileus

\section{HASIL PENELITIAN}

\section{Karakteristik Responden}

Dalam penelitian ini menggunakan beberapa karakteristik responden, karakteristik yang dimaksud merupakan gambaran secara umum responden yang terpilih pada penelitian ini, dapat dilihat pada Tabel 1

Syeila Ainun Nisa ${ }^{1}$, Yohni Wahyu Finansah2 ${ }^{2}$, Uning Marlina3, Syaiful Rochman ${ }^{4}$ yakni jenis kelamin, rata-rata usia, rata-rata lama dirawat, rata-rata lama dirawat sebelum operasi, ratarata lama operasi, persentase pasien masuk ICU, dan persentase dilakukan transfusi darah.

\section{Karakteristik Responden Berdasarkan :}

\section{a. Jenis Kelamin}

paralitik dan obstruktif, pada tahun 2017 tercatat 27 kasus. Sedangkan pada tahun 2018 tercatat 29 kasus. Berdasarkan data yang ada masih banyak terjadinya kasus ileus obstruktif dan sampai sekarang belum ada penelitian mengenai perbedaan karakteristik bowel obstruction oleh sebab itu peneliti ingin melakukan penelitian di Rumah Sakit Umum Daerah Dr. Soegiri Lamongan dengan judul Perbedaan Karakteristik Partial Bowel Obstruction dan Total Bowel Obstruction Pada Pasien Ileus di Rumah Sakit Umum Daerah DR. Soegiri Lamongan tahun 20152019. Penelitian ini bertujuan untuk mencari tahu perbandingan karakteristik pasien kasus ileus berdasarkan jenis kelamin, usia, lama dirawat, lama dirawat sebelum operasi dan lama operasi.

\section{METODE PENELITIAN}

Sampel pada penelitian ini adalah pasien yang terdiagnosa ileus berdasarkan hasil laparatomi di RSUD DR Soegiri Lamongan. Penelitian ini merupakan jenis penelitian deskriptif analitik dan metode yang digunakan adalah metode cross sectional. Sampel pada penelitian ini adalah pasien yang terdiagnosa ileus di RSUD DR Soegiri Lamongan berdasarkan hasil laparatomi. Pengambilan sampel menggunakan metode total sampling yakni data dari tahun 2015-2019. Sampel yang digunakan merupakan data sekunder yaitu rekam medis yang dilaksanakan pada Desember 2019 - Januari 2020. Analisa data pada penelitian ini terdapat analisa univariat dengan menggunakan uji t-test dan Analisa bivariat yang menggunakan uji chisquare. 
Pada Tabel 1, dijelaskan bahwa sebagian besar responden berjenis kelamin laki-laki. Nilai signifikansi yang didapatkan sebesar $0,409(\mathrm{p}<0,05)$. Sehingga dari data yang diperoleh, berdasarkan jenis kelamin responden tidak menunjukkan perbedaan yang signifikan.

\section{b. Usia}

Pada Tabel 1, dijelaskan bahwa sebagian besar responden berusia kurang dari 65 tahun. Nilai signifikansi yang didapatkan sebesar 0,002 $(\mathrm{p}<0,05)$. Sehingga dari data yang diperoleh, berdasarkan usia ditemukan adanya perbedaan yang signifikan oleh peneliti.

\section{c. Lama Dirawat}

Pada Tabel 1, dapat di pahami bahwa sebagian besar dari lamanya dirawat responden, menunjukkan hasil yang kurang dari rata-rata. Nilai signifikansi yang didapatkan sebesar $0,917 \quad(\mathrm{p}<0,05)$. Sehingga dari data yang diperoleh berdasarkan lama dirawat responden, tidak menunjukkan perbedaan yang signifikan.

\section{d. Lama Dirawat Sebelum Operasi}

Pada Tabel 1, dapat dipahami bahwa sebagian besar lama dirawat sebelum operasi kurang dari 2 hari. Nilai signifikansi yang didapatkan sebesar 0,340 $(p<0,05)$. Sehingga berdasarkan lama dirawat sebelum operasi responden tidak menunjukkan perbedaan signifikan.

Tabel 1 Karakteristik Responden

\begin{tabular}{|c|c|c|c|c|}
\hline & \multicolumn{2}{|c|}{ Bowel Obstruction } & \multirow{2}{*}{ Persentase } & \multirow[t]{2}{*}{$p$} \\
\hline & Partial & Total & & \\
\hline \multicolumn{5}{|l|}{ Jenis Kelamin } \\
\hline Laki-laki & 11 & 8 & $57,6 \%$ & \multirow{2}{*}{0,409} \\
\hline Perempuan & 6 & 6 & $42,4 \%$ & \\
\hline \multicolumn{5}{|l|}{ Usia } \\
\hline$<65$ tahun & 14 & 7 & $63,6 \%$ & \multirow{2}{*}{0,002} \\
\hline$\geq 65$ tahun & 3 & 9 & $36,4 \%$ & \\
\hline \multicolumn{5}{|l|}{ Lama dirawat } \\
\hline$<$ Rata-rata $(<10$ hari $)$ & 11 & 11 & $66,67 \%$ & \multirow{2}{*}{0,917} \\
\hline$>$ Rata-rata (>10 hari) & 6 & 5 & $33,33 \%$ & \\
\hline \multicolumn{5}{|c|}{ Lama dirawat sebelum operasi } \\
\hline$<2$ hari & 8 & 11 & $57,6 \%$ & \multirow{2}{*}{0,340} \\
\hline$\geq 2$ hari & 9 & 5 & $42,4 \%$ & \\
\hline \multicolumn{5}{|l|}{ Lama Operasi } \\
\hline$<$ Rata-rata & 8 & 6 & $42,4 \%$ & \multirow{2}{*}{0,593} \\
\hline$\geq$ Rata-rata & 9 & 10 & $57,6 \%$ & \\
\hline \multicolumn{5}{|l|}{ Masuk ICU } \\
\hline $\mathrm{Ya}$ & 6 & 11 & $51,5 \%$ & \multirow{2}{*}{0,240} \\
\hline Tidak & 9 & 7 & $48,5 \%$ & \\
\hline \multicolumn{5}{|l|}{ Transfusi Darah } \\
\hline $\mathrm{Ya}$ & 1 & 1 & $6 \%$ & \multirow{2}{*}{0,966} \\
\hline Tidak & 16 & 15 & $94 \%$ & \\
\hline
\end{tabular}

\section{e. Lama Operasi}

Pada Tabel 1, dapat dipahami bahwa sebagian besar lama operasi $\geq$ rata-rata. Nilai signifikansi yang didapatkan sebesar $0,593 \quad(\mathrm{p}<0,05)$. Sehingga berdasarkan lama operasi tidak ada perbedaan signifikan.

\section{f. Masuk ICU}


Pada Tabel 1, dapat dipahami bahwa sebagian besar responden masuk ICU. Nilai signifikansi yang didapatkan sebesar $0,240 \quad(p<0,05)$. Sehingga berdasarkan data yang diperoleh, peneliti menyimpulkan bahwa berdasarkan pasien yang masuk ICU tidak ditemukan perbedaan signifikan.
Pada Tabel 1, dijelaskan bahwa dalam penelitian ini sebagian besar responden tidak melakukan transfusi darah. Nilai signifikansi yang didapatkan sebesar $0,966(\mathrm{p}<0,05)$. Sehingga berdasarkan transfusi darah peneliti tidak menemukan adanya perbedaan yang signifikan.

\section{g. Transfusi Darah}

Tabel 2 Perbedaan Karakteristik Partial dan Total Bowel Obstruction Berdasarkan :

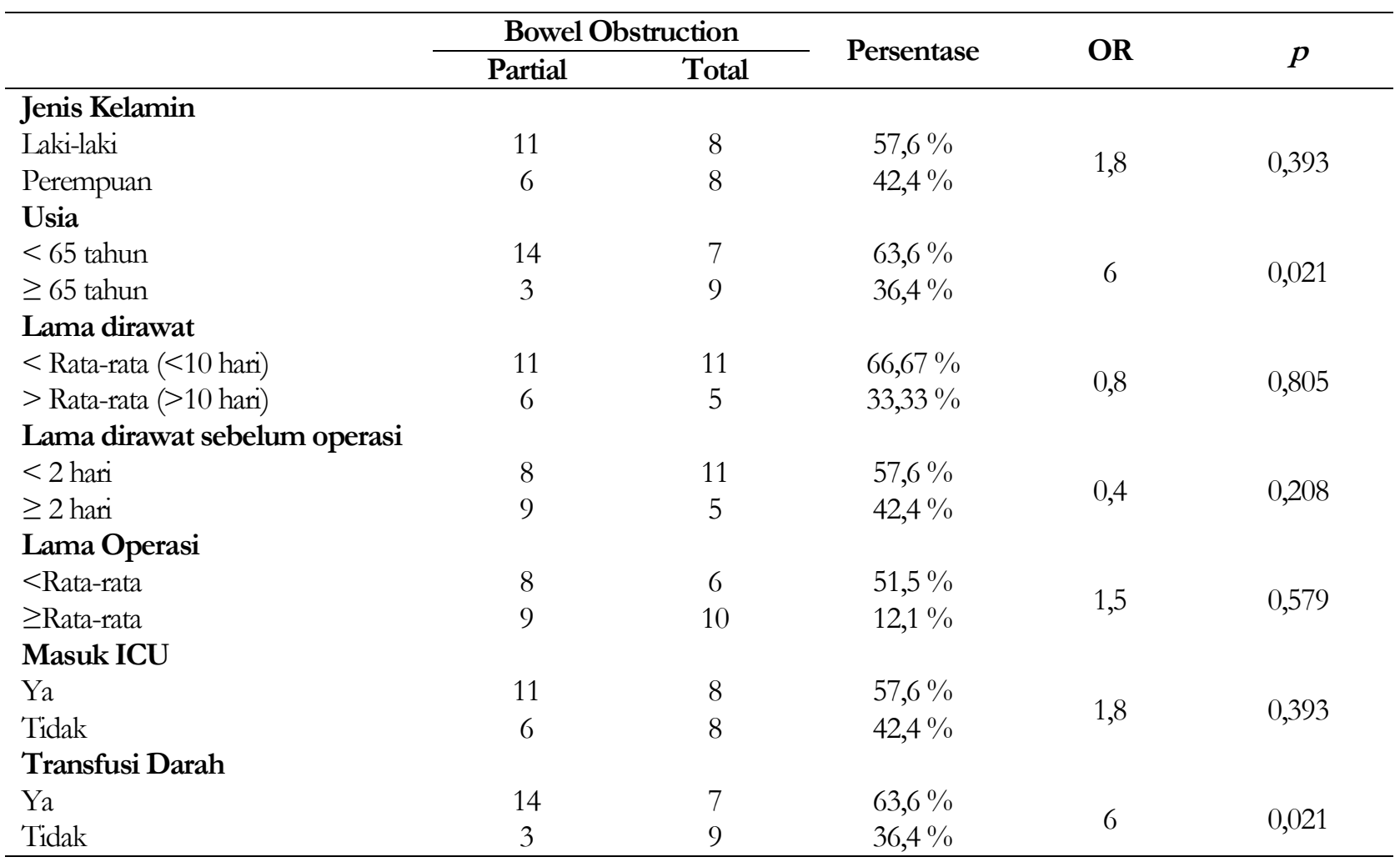

\section{Perbedaan Karakteristik Partial dan Total Bowel Obstruction}

Pada penelitian ini mencari tahu adanya perbedaan karakteristik antara partial dan total bowel obstruction berdsarkan jenis kelamin, rata-rata usia, rata-rata lama dirawat, rata-rata lama dirawat sebelum operasi, ratarata lama operasi, dapat dilihat pada Tabel 2 yakni merupakan hasil dari penelitian yang menggunakan uji Chi-Square untuk mengetahui adanya perbedaan.
Perbedaan Karakteristik Partial dan Total Bowel Obstruction Berdasarkan :

\section{Jenis Kelamin}

Pada Tabel 2, didapatkan nilai signifikansi 0,393 $(p<0,05)$. Dari data yang diperoleh terbukti bahwa berdasarkan jenis kelamin tidak ada perbedaan karakteristik.

\section{Usia}

Pada Tabel 2 didapatkan nilai signifikansi sebesar $0,021(p<0,05)$. Dari data yang diperoleh terbukti 
bahwa berdasarkan usia terdapat perbedaan karakteristik. Responden berusia kurang dari 65 tahun beresiko 6 kali lebih besar mengalami partial bowel obstruction dibanding responden yang usianya lebih dari sama dengan 65 tahun.

\section{Lama Dirawat}

Pada Tabel 2, didapatkan nilai signifikansi 0,805 $(\mathrm{p}<0,05)$. Dari data yang diperoleh terbukti bahwa berdasarkan lama dirawat tidak terdapat perbedaan karakteristik.

\section{Lama Dirawat Sebelum Operasi}

Pada Tabel 2, didapatkan nilai signifikansi 0,208 $(p<0,05)$. Dari data yang diperoleh terbukti bahwa berdasarkan lama dirawat sebelum operasi tidak terdapat perbedaan karakteristik.

\section{Lama Operasi}

Pada Tabel 2 diatas, didapatkan nilai signifikansi $0,579(p<0,05)$. Dari data yang diperoleh terbukti bahwa berdasarkan lama operasi tidak terdapat perbedaan karakteristik.

\section{PEMBAHASAN}

\section{Berdasarkan Jenis Kelamin :}

Pada penelitian ini menunjukkan bahwa sebagian besar responden jenis kelaminnya adalah laki-laki dengan persentase $57,6 \%$. Tidak ditemukan adanya perbedaan karakteristik partial dan total bowel obstruction berdasarkan jenis kelamin. Sejalan dengan penelitian Serin A et al (2017) yang menyatakan bahwa laki-laki paling banyak menderita ileus obstruktif dengan jumlah penderita 26 orang dengan persentase 65\% (2). Nelly P (2012) dalam penelitiannya menunjukkan bahwa pasien rawat inap mayoritas berjenis kelamin laki-laki 64 orang dengan persentase $56,8 \%{ }^{5}$.

\section{Berdasarkan Usia :}

Pada penelitian ini menunjukkan bahwa sebagian besar responden berusia kurang dari 65 tahun dengan persentase 63,6\%. Didapatkan perbedaan karakteristik partial dan total bowel obstruction berdasarkan usia. Hasil penelitian diatas sejalan dengan penelitian Laysa $\mathrm{K}$, Dennison $\mathrm{H}$, Hendra (2013) yang menyatakan bahwa mayoritas pasien berusia 15-49 tahun 51 orang dengan presentasi 54.8\% (0). Serin A et al (2017) dalam penelitiannya menyatakan bahwa mayoritas berusia 6-11 tahun dengan jumlah sampel 8 orang dan persentase $20 \%{ }^{2}$.

\section{Berdasarkan Lama Dirawat :}

Pada penelitian ini menunjukkan bahwa sebagian besar responden yang dirawat kurang dari rata-rata (10 hari). Tidak ditemukan adanya perbedaan karakteristik partial dan total bowel obstruction berdasarkan lama dirawat. Penelitian yang dilakukan oleh Markogiannakis H et al (2007) dapat mendukung hasil penelitian diatas yakni menunjukkan bahwa rata-rata lama dirawat pasien selama 7 hari (7). Nelly P (2012) juga melakukan penelitian yang menjelaskan bahwa rata-rata lama pasien dirawat selama 8 hari (5). Laysa K, Dennison H, Hendra (2013) melakukan penelitian serupa yang menunjukkan bahwa rata-rata lama perawatan pasien selama 7 hari (6).

\section{Berdasarkan Lama Dirawat Sebelum Operasi :}

Pada penelitian ini menunjukkan bahwa sebagian besar lama dirawat sebelum operasi kurang dari 2 hari. Tidak didapatkan perbedaan karakteristik partial dan total bowel obstruction berdasarkan lama dirawat sebelum operasi. Penelitian yang dilakukan Markogiannakis H et al (2007) berbeda dengan hasil penelitian diatas yakni menunjukkan bahwa rata-rata lama pasien dirawat sebelum operasi selama 2 hari $^{7}$.

\section{Berdasarkan Lama Operasi :}

Pada penelitian ini dapat dilihat bahwa mayoritas responden dengan lama operasi kurang dari rata-rata. Tidak ditemukan adanya perbedaan karakteristik partial dan total bowel obstruction berdasarkan lama operasi. Hasil penelitian diatas 
didukung dengan penelitian Yuwono (2013) yang menjelaskan bahwa lama operasi saat laparotomi $<135$ menit $^{8}$.

\section{KESIMPULAN}

Karakteristik responden di RSUD Dr. Soegiri Lamongan mayoritas berjenis kelamin laki-laki, berusia $<65$ tahun, lama dirawat $<10$ hari, lama dirawat sebelum operasi $<2$ hari, lama operasi ratarata 39 menit pada partial bowel obstruction dan 42 menit utuk total bowel obstruction), 51,5\% pasien masuk ICU, dan 6,1\% dilakukan transfusi darah. Perbedaan karakteristik pasien partial bowel obstruction dan

\section{DAFTAR PUSTAKA}

1. Depkes R. Profil Kesehatan Republik Indonesia. 2010.

2. Serin, A., Simangunsong, B., \& Siagian P. Karakteristik Penderita Ileus Obstruksi Yang Rawat Inap Di RSUD Deli Serdang Lubuk Pakam Periode 2015-2016. J Kedokt Methodist. 2017;10(1):31-4.

3. Sjamsuhidajat, R \& Wim de J. Buku Ajar Ilmu Bedah. Edisi 4. Jakarta: EGC; 2017.

4. Depkes. Fortune t.a.v. Peter Verloop Dijk 182731 AA Benthuizen. 2015;27-9.

5. Pasaribu N. Universitas Sumatera Utara. Universitas Sumatera Utara; 2012.

6. Kasminata L, Dennison, Herman H. Gambaran Karakteristik Penderita Ileus Obstruktif Rawat Inap Di Rsud Raden Mattaher Jambi. 2013.

7. Markogiannakis $\mathrm{H}$, Messaris $\mathrm{E}$, Dardamanis D, Pararas N, Tzertzemelis D, Giannopoulos P, et al. Acute mechanical bowel obstruction: Clinical presentation, etiology, management and outcome. World J Gastroenterol. 2007;13(3):432-7.

8. Yuwono Y. Pengaruh Beberapa Faktor total bowel obstruction pada pasien ileus hanya pada usia pasien, sedangkan jenis kelamin, lama dirawat, lama dirawat sebelum operasi dan lama operasi tidak didapatkan perbedaan yang signifikan. Penelitian ini diharapkan dapat menambah dan memperluas pengetahuan tentang penyakit ileus dan dapat digunakan sebagai bahan untuk penelitian, serta sebagai bahan informasi bagi tenaga medis tentang Perbedaan Karakteristik Partial Bowel Obstruction Dan Total Bowel Obstruction Pada Pasien Ileus di RSUD Dr. Soegiri Lamongan sehingga dapat mendukung pelaksanaan pengobatan pada penderita ileus

Risiko Terhadap Kejadian Surgical Site Infection (SSI) Pada Pasien Laparotomi Emergensi. Jambi Med J. 2013;1(1). 